\title{
Anticipation of Individuals with Communication Disabilities: Problem Current State Review
}

\author{
Nadezhda A. Saifullina*1, Anna I. Akhmetzyanova 2 \\ 1,2 Kazan Federal University \\ Email: logopedkazan@mail.ru, Contact: 89276710877
}

\section{Received: 21st October 2017 Accepted: 16th November 2017, Published: 31st December 2017}

\begin{abstract}
The urgency of the problem is specified by the global growth of children with severe speech disorders, the need to develop a comprehensive psychological care for the people of this category. According to the generally accepted principles of modern psychology, verbal behavior is based on probabilistic forecasting. Probabilistic forecasting, anticipation determines a particular type of human behavior - a verbal one. The purpose of this article is to carry out the theoretical analysis of domestic psychologist works, revealing the main aspects of modern research on the anticipation of persons with communication disabilities. The need for more in-depth study of speech function communicative components of the speech function is revealed, one of which is prediction. Among the persons with communication disabilities, this component has distinctive features that have not been subjected to a comprehensive study. The materials of the article can be used in the work of psychologists and the experts of the correctional profile
\end{abstract}

Keywords: Anticipation, Probabilistic Prediction, Violation of Communication Means

\section{Introduction}

One of the most important higher mental functions, which play a priority role in mental development, is the speech function. It is the development and the mastery of communication skills that creates the foundation for child's specific social contacts. The global nature of this problem is conditioned by the indicators of the statistics data. In recent years there has been a steady increase in the number of children with disabilities, including those who suffer from severe speech disorders. As of January 1, 2015, the number of children with health opportunities was 590.4 thousand in the Russian Federation, which in dynamics characterizes the increase of this category number over a three-year period (in 2013 - 582.2 thousand, in 2012 571.5 thousand). The number of special educational institutions for children with severe speech pathology is 65 with 10,964 of students.

At the present time, the attention of psychologists is directed to a new topical trend, namely, the study of anticipatory solvency characteristics among the persons with speech pathology. The forecasting of speech reflects some fragment of the previous experience in the unity of its perceptive, cognitive and affective characteristics, the perspective of this experience and the attitude towards it (Ananiev, 2008). The anticipation of persons with communication disabilities has distinctive characteristics, however, a holistic study of the anticipatory consistency of individuals with communication disorders was not conducted.

Analyzing the problem of the communicative function of anticipation study, it is worth noting that in many studies the processes of foresight act as the function of highly organized processes and the conscious activity of a subject. It has a clear relation: the goal and the expected result determine the activity of an individual. Therefore, without anticipation it is impossible either to form a goal of an activity, or to identify the tasks, or its planning, or the current regulation, i.e. even a brief examination of activity structure shows that the processes of anticipation "permeate" all of its elements.

The significance and the relation of anticipatory solvency with speech activity were studied and described in the works of foreign and domestic scientists: A. Foucart et al. (2014), D.M. Clark (2003), R.M. Frumkina. (1974), I.A. Zimnyaya (2001), E.A. Sergienko (2015), A.I. Akhmetzyanova (2014). They stressed that anticipation is one of the basic processes that determines a full-fledged speech development. According to the works of the listed authors, anticipation is the mechanism for "pre-tuning" of speech processes, ensuring the ability to reproduce and understand an addressed speech.

One of the priority areas of special psychology is the high level of social adaptation of persons suffering from speech pathology. T. N. Volkovskaya (2016) notes that the possibility of psychological characteristics of children differentiation with impaired communication means provides the analysis of communicative disadaptation structure from the perspective of the traditional approach in psychology to the evaluation of mental activity structure on the basis of its motivational and operational component allocation. The communication competence can be improved due to the development of anticipatory abilities of persons with communication disabilities. This aspect is the fundamental basis for the successful socialization of this category of persons.

At its core, anticipation is an integral part of any mental process, among which a special place is taken by speech (León-Cabrera, Rodríguez-Fornells \& Morís, 2017). The study of anticipatory solvency is of special 
Helix Vol. 8(1): 2506- 2511

interest to experts when they deal with various types of speech pathology. A number of studies showed that in various forms of speech behavior within the norm (for example, in the perception and the processing of speech information), a person relies on a speech forecast (Jackson et al., 2017). The works by R. M. Frumkin (1974) emphasize that the speech mechanisms of a man have a certain organization of words by frequency.

The strengthening of anticipation is carried out according to the general laws of psyche maturation. The retardation factor of the anticipation development is possible due to the influence of unfavorable external and internal circumstances at the stage of early ontogenesis, which can lead to total or partial asynchrony of intellectual activity.

\section{Methods}

The leading approach to the solution of the problem is the fundamental system-level concept of anticipation (Lomov \& Surkov, 1980). According to this approach, anticipation is the form of anticipatory reflection of reality, which covers the whole spectrum of mental functions manifestations, including communicative one.

\section{Results}

The traditional field of current research trends study of modern psychological science is the analysis of publications that are presented in the world scientific journals. In order to determine the degree of anticipation phenomenon scientific development, the bibliometric analysis of the information space of modern psychological research on the most popular databases was conducted: "Scopus", "Web of Science", "E-library".

We conducted the bibliometric analysis of anticipation phenomenon study for the last 5 years (2012 - 2016) on the world largest database "Scopus". The selection of publications was made according to the key word "anticipation".

The analysis included the publications for the last 5 years (2012-2016), their total number was 19937 works.

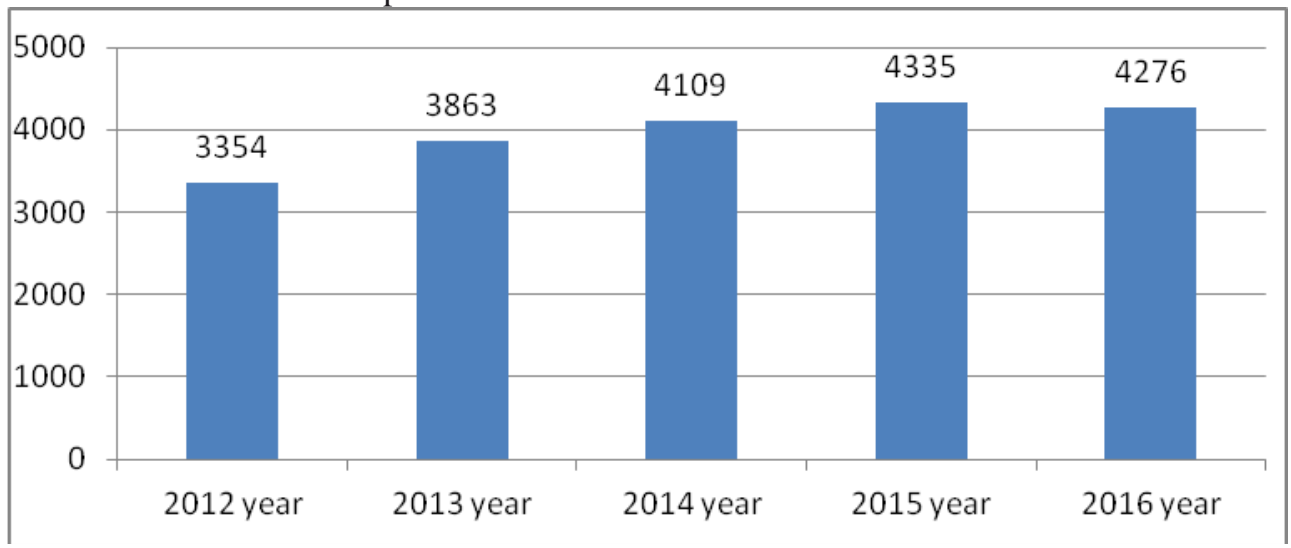

Fig.1. Results of Bibliometric Analysis concerning the Phenomenon of Anticipation according to the Scopus Database.

The analysis of the publication activity dynamics towards the study of anticipation phenomenon for the period 2012-2016 points to an intensive growth of publications number among foreign researchers.
Let us turn to a similar bibliometric analysis of anticipation phenomenon for the last 5 years (2012 2016) based on "Web of Science" database. The selection of publications was also performed according to the keyword "anticipation". The total number of works for 5 years (2012-2016) was 4759.

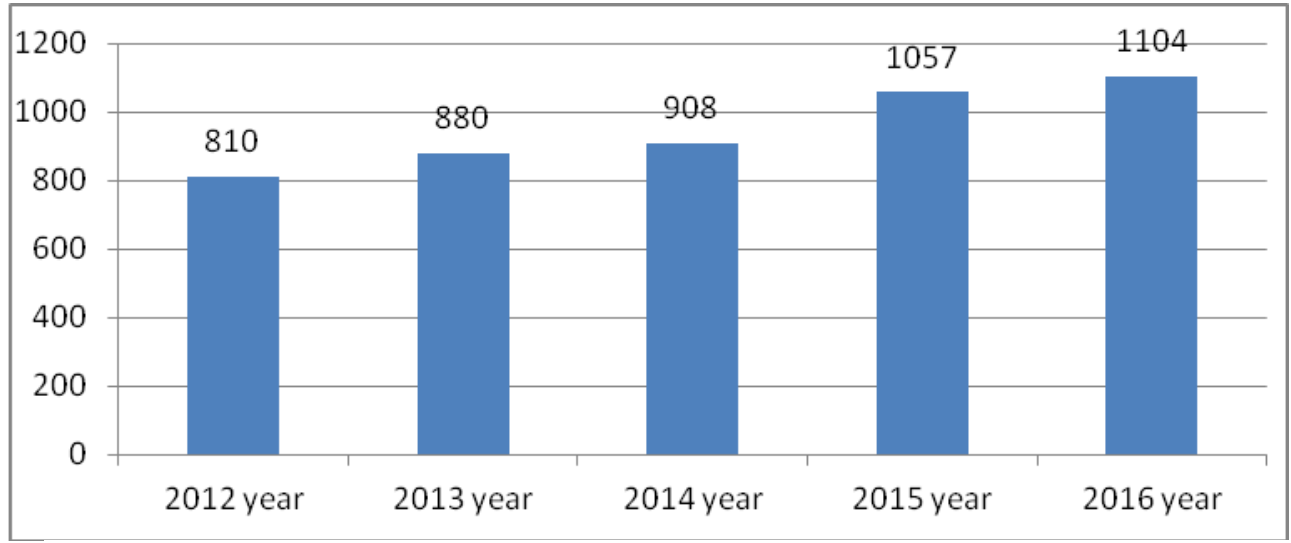

Fig.2. Results of Anticipation Phenomenon Bibliometric Analysis in "Web of Science" Database. 
Helix Vol. 8(1): 2506- 2511

The result of bibliometric analysis method application in the "Web of Science" database is the revealing of an intensive positive dynamics of the research interest in the phenomenon of anticipation.

The bibliometric analysis of anticipation phenomenon study for the last 5 years (2012 - 2016), conducted according to the "E-library" database on the keyword "anticipation", revealed lower rates of publication activity.

The analysis included the publications for the last 5 years (2012-2016), their total number was 214 works.

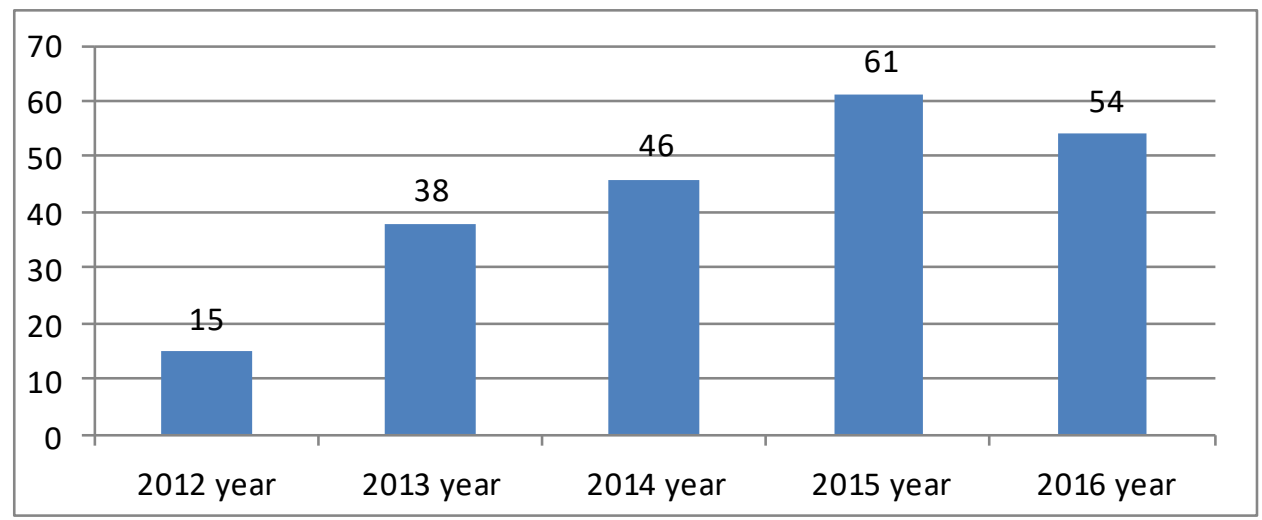

Fig.3. The Results of the Bibliometric Analysis of Anticipation Phenomenon in "E-library" Database

The demonstrated results indicate a significant difference in the publication activity on the issue of anticipation phenomenon study by domestic and foreign researchers.
We give the visual comparison of bibliometric analysis results concerning the phenomenon of anticipation according to the databases "Scopus", "Web of Science", "E-library" (See Fig.4).

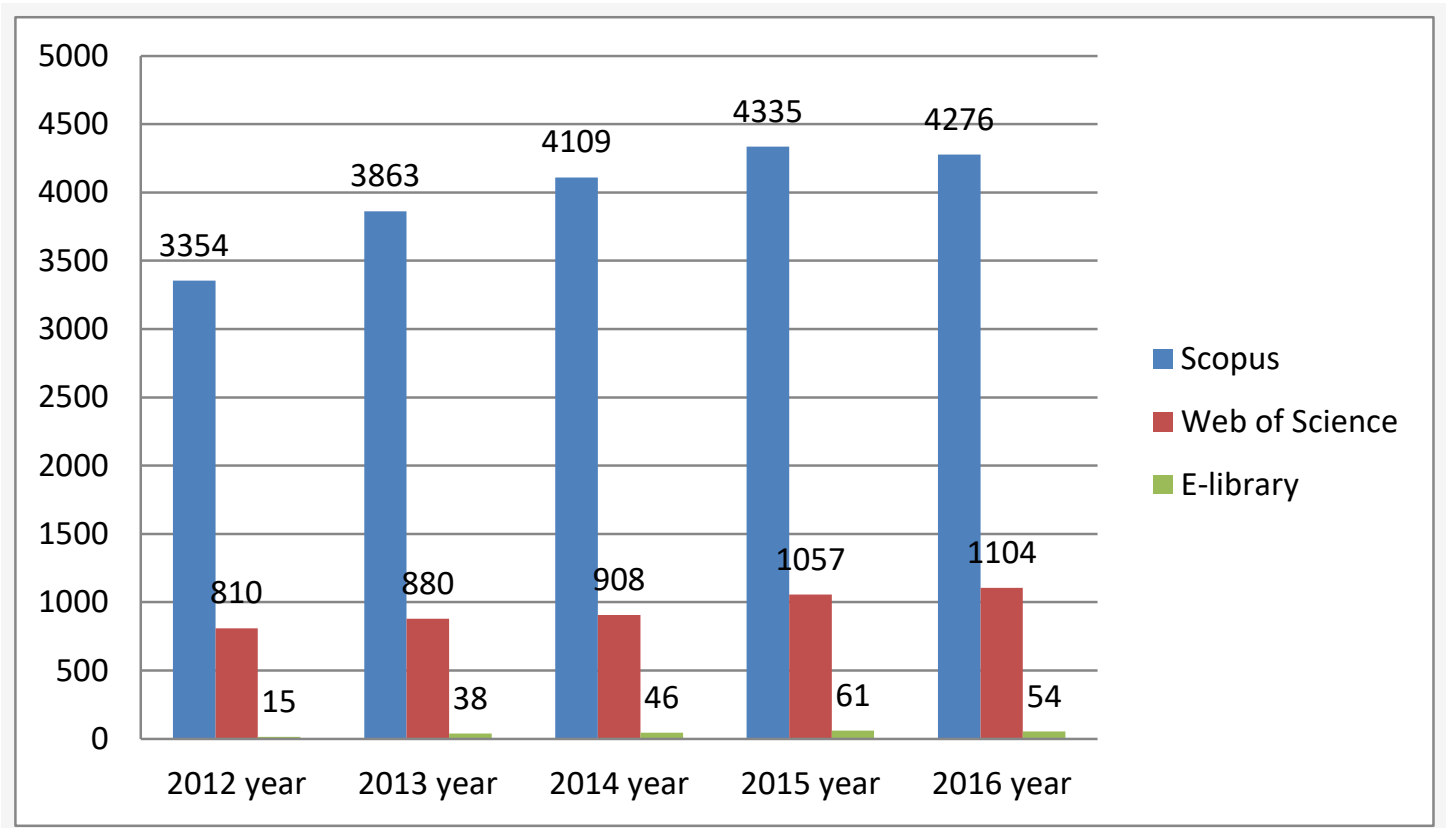

Fig.4. The Results of the Comparative Bibliometric Analysis concerning the Phenomenon of Anticipation according to the Databases "Scopus", "Web of Science", "E-library"

As can be seen from Fig. 4, the scientific works of domestic scientists, the reflection of anticipation phenomenon study results has significantly lower quantitative indicators. This opens up the possibilities for problem solution by the qualitative analysis of modern foreign scientific research.

\section{Discussion}

In addition to the quantitative analysis, the work of Russian psychologists on the problem of anticipation study among the persons with communication disabilities was analyzed in detail.

The communicative function of anticipation is inextricably linked with the regulatory and cognitive function, they are inseparable in every act of human behavior. It is proved that the level of anticipation 


\section{Helix Vol. 8(1): 2506- 2511}

development is the indicator of mental development level in general (Lomov \& Surkov, 1980). The mechanism of anticipation plays a special role in the process of reading, providing a direct perception and the understanding of syntactic structures.

The study of anticipation mechanisms in speech activity, in the context of reading, was conducted by O.N. Bershanskaya (2008), S.A. Matalyga (2009), L. Yu. Shishkina (2006). They considered each operation of anticipation mechanisms from the positions of functionality and identified the following operations:

1) Perception-familiarization. The concept of perception is rather voluminous, but only the process of perception is considered concerning receptive activity. Each subsequent operation of the anticipatory mechanisms is carried out through the perception of the grammatical phenomenon, which is conditioned by the nature of the receptive type of speech activity. That is why "the strength of knowledge mastering directly depends on the primary perception of the material".

2) The identification of significant signs leading to the realization of form. This operation was considered as the perception and an independent controlled analysis of an object of mastery: the identification of essential features, rules and the determination of activity guidelines.

3) Identification in a new context. Sentence models with characteristic features of their structure, the awareness of grammatical meaning and function are developed in mind.

4) Differentiation. The theory of perception describes that differentiation is realized if "a number of stimuli change from the perceived one as homogeneous to the perceived one as heterogeneous so that the distinctive aspects of this series become different".

5) Recognition. This operation is aimed to divide the aggregate of structures that have common signs of a structure development, by types. The process is based on the comparison of object mastery characteristics with the characteristics of other known objects in a new context, which leads to the conclusion about their most plausible correspondence.

In the study of anticipation in speech activity, the concept proposed by R. M. Frumkina (1974) occupies a special place, according to which the subject develops a speech experience that contains certain subjective ideas about the probabilistic hierarchy of speech elements in the process of speech practice. The functioning of anticipation mechanisms in speech activity is conditioned by two groups of factors: 1) individually - typological (linguistic experience, age, gender); 2) linguistic (context).

However, in addition to these factors, individual psychological characteristics of the individual also influence the anticipation consistency, both in general and in speech activity (Appelbaum L. G., et al., 2014). For example, for the development of certain style and individual psychological features, the anticipation mechanisms can be the basis, and the set of specific personality traits is able to determine the style of anticipation activity (Solobutina, 2015). It should be noted that in some types of dysontogeny during infancy, infants have slowing down or the partial stop of probabilistic forecasting and anticipation development.

A vivid example is an early childhood autism. E.A. Sergienko (1988) stressed the essential role of anticipation in the development of higher mental functions and noted that the violation of this process during the early stages of child development can cause specific non-violent disorders of intellectual and mental development. The author revealed the specifics of anticipatory solvency phenomenon in the period of early ontogenesis, an experimental analysis of the elementary forms of anticipation was conducted and experimental and theoretical approaches to the study of anticipation were revealed.

A special contribution to the study of anticipatory solvency characteristics among the children with speech disorders was made by A.I. Akhmetzyanova (2014). She carried out a comprehensive, systematic assessment of anticipation and probabilistic prediction functioning among the children of six years with a speech pathology and the assessment of the relationship between these two parameters. The author proved that for the greater part of children with verbal pathology an adequate prognosis of events is developed at a much slower rate and is accompanied by a significant number of "abstraction errors".

\section{Conclusions}

The success of speech prediction is influenced by the knowledge of the general meaning of an utterance, i.e. "as the general meaning of the whole context becomes known, the prediction is performed easier" (Jackson, Yaruss, Quesal, Terranova, \& Whalen, 2015). The prediction of speech reflects the fragment of the previous experience in the unity of its perceptive, cognitive and affective characteristics, the perspective of this experience and the attitude towards it. Among the persons with speech pathology, this component has distinctive features, which have not been studied in complex.

The theoretical analysis made it possible to draw the conclusion about the features of individual anticipation with the means of communication disorder and the characteristics of anticipation communicative function. Outside of a special attention to their speech, this category of people is inactive, they are not initiators of communication, they do not accompany life situations with stories, they are unable to anticipate an interlocutor's address, supplement and continue a dialogue constructively. This causes a reduced communicative orientation of speech in this category. 
The generalization of approaches to the problem of anticipatory consistency shows that a systemic and hierarchical principle is manifested in anticipatory mental activity (Dignath \& Janczyk, 2017). Therefore, anticipation is considered not only as a spatial-temporal pre-emption, but also as the degree of completeness and the accuracy of prediction. It was revealed that the choice of speech behavior strategy is interrelated with the frequency-probabilistic organization of the dictionary in the memory of a native speaker, the frequency of certain word occurrence, speech stamps, cliches, high-frequency word combinations are determined by the frequency of occurrence in an individual's experience.

\section{Summary}

Dealing with the persons who have communication disabilities, it is possible to rely on the regulatory function of anticipation and use it as a system-forming component of a targeted correctional process organization. Thus, it is possible to provide a qualitatively new level of active and conscious activity of individuals with the disorders of communication in the process of complex psychological and pedagogical rehabilitation and socialization. This result will be achieved through the participation of this category of persons in the planning, organization and the conduct of some elements of corrective activities.

It should be noted that, despite the availability of qualitative research, structurally developed approaches to the problem of anticipatory solvency, the problem of a comprehensive study of the anticipation communicative function remains particularly relevant in the scientific community.

\section{Acknowledgements}

The work is performed according to the Russian Government Program of Competitive Growth of Kazan Federal University.

The research was carried out with the support of the Russian Foundation for Basic Research and the Government of the Republic of Tatarstan within the framework of the research project № 17-16-16004 "Prognostic competence of younger schoolchildren with disabilities in the prevention of deviations".

\section{References}

[1] Ananiev B.G. (2008). Personality, subject of activity, individuality. M.: Direct-Media, 134.

[2] Akhmetzyanova A.I. (2015). Theoretical analysis of ideas about the development of mental reflection anticipatory function. Humanities and Social Sciences, 3,233-249

[3] Bershanskaya O.N. (2008). Mobilizing stage of literary reading lessons [methods of teaching through subjective and material perspectives]. Elementary school, 7, 15-20.

[4] Sergienko E.A. (2015). Development of the mental model in preschool age. The world of psychology, 1,53-64.
[5] Frumkina R.M. (2001). Psycholinguistics. Textbook for university students. M.: Academy, 321.

[6] Akhmetzyanova, A.I. (2014). Spatial and temporal elements of anticipation consistency of children with general speech retardation. American Journal of Applied Sciences, 11 (7), 1031-1035.

DOI: 10.3844/ajassp.2014.1031.1035

[7] Appelbaum, L. G., et al. (2014). The dynamics of proactive and reactive cognitive control processes in the human brain. Journal of Cognitive Neuroscience, 26 (5), 1021-1038.

[8] Baykova, A. D., Akhmetzyanova, A. I., \& Artemyeva, T. V. (2016). The relationship between tendency to deviant behaviour and level of subjective control and anticipational consistency in schoolchildren. Journal of Organizational Culture, Communications and Conflict, 20, 1.

[9] Clark, D. M. (2003). Anticipatory processing in social anxiety: two pilot studies. Journal of Behaviour Therapy and Experimental Psychiatry, 34, 205-218.

[10] Dignath, D., Janczyk, M. (2017). Anticipation of delayed action-effects: learning when an effect occurs, without knowing what this effect will be. Psychological Research, 81 (5),10721083.

[11] Foucart, A., Martin , C. D., Moreno, E. M., \& Costa, A. (2014). Can Bilinguals See It Coming? Word Anticipation in L2 Sentence Reading. Journal of Experimental Psychology: Learning, Memory, and Cognition. http://dx.doi.org/10.1037/a0036756

[12] Jackson, E. S., Yaruss, J. S., Quesal, R. W., Terranova, V., \& Whalen, D. H.(2015) . Responses of adults who stutter to the anticipation of stuttering. Journal of Fluency Disorders, 45, 38-51.

[13] Zimnyaya, I.A. (2001). Linguistic Psychology of Speech Activity. M.: Moscow Psychological Social Institute, Voronezh: "MODEK" Scientific Production Association, 432 p.

[14] León-Cabrera P., Rodríguez-Fornells, A., \& Morís, J. (2017). Electrophysiological correlates of semantic anticipation during speech comprehension. Neuropsychologia, 99, 326334.

[15] Volkovskaya T. N. (2016). Theoretical aspects of the communicative exclusion of children with speech. Correctional pedagogy: theory and practice, 4, 8-12.

[16] Report of the Ministry of labour and social protection of the Russian Federation from December 15, 2015 "State report on the situation of children and families with children in the Russian Federation in 2014" URL:http://msh.rk.gov.ru/rus/file/gosudarstvenn yj-doklad-o-polozhenii-detej-i-semejimeyushhikh-detej-v-rossijskoj-federacii-za2015-god.pdf 


\section{Helix Vol. 8(1): 2506- 2511}

[17] Sergienko E.A. (1988). Anticipation in visual behaviour of infants. Abstract of 11 European conference on visual perception. Bristol: United Kingdom in "Perception", 8, p. 1284

[18] Solobutina M.M. (2015). Insights into Anticipation Capacity Development Programme at Interpersonal Interaction. Review of European Studies, 7(5), 137-145. http://dx.doi.org/10.5539/res.v7n5p137

[19] Rajsic, J., Ouslis, N. E., Wilson, D.E., Pratt, J. (2017). Looking sharp: Becoming a search template boosts precision and stability in visual working memory. Attention, Perception, \& Psychophysics, 79 (6), 1643-1651 